\title{
Pharmacokinetics of oral valganciclovir solution and intravenous ganciclovir in pediatric renal and liver transplant recipients
}

M.D. Pescovitz, R.B. Ettenger, C.F. Strife, J.R. Sherbotie, S.E. Thomas, S. McDiarmid, S. Bartosh, J. Ives, M.R. Bouw, J. Bucuvalas. Pharmacokinetics of oral valganciclovir solution and intravenous ganciclovir in pediatric renal and liver transplant recipients. Transpl Infect Dis 2010: 12: 195-203. All rights reserved

Abstract: In an open-label, prospective, pharmacokinetic assessment, we evaluated total drug exposure (area under the curve [AUC]) of intravenous (IV) ganciclovir (GCV) and oral (p.o.) valganciclovir when normalized for body surface area (BSA) in pediatric liver $(n=20)$ and renal $(n=26)$ transplant patients Reference doses for IV GCV $(200 \mathrm{mg} /$ $\left.\mathrm{m}^{2}\right)$ and p.o. valganciclovir $\left(520 \mathrm{mg} / \mathrm{m}^{2}\right)$ were based on adult doses, and adjusted for BSA initially, and BSA and renal function (estimated via creatinine clearance [CrCL]) thereafter. Renal transplant patients received GCV on days $1-2$, valganciclovir $260 \mathrm{mg} / \mathrm{m}^{2}$ on day 3 , and valganciclovir $520 \mathrm{mg} / \mathrm{m}^{2}$ on day 4 . Liver transplant patients received twice daily GCV from enrollment to day 12 , and then valganciclovir twice daily on days 13-14. GCV pharmacokinetics were described using a population pharmacokinetic approach. Type of solid organ transplant (kidney or liver) had no effect on GCV pharmacokinetics. Median GCV exposure following valganciclovir $520 \mathrm{mg} / \mathrm{m}^{2}$ was similar to that with IV GCV, and to that reported in adults. Patients $<5$ years of age had AUC values approximately $50 \%$ of those compared with older age ranges; dosing based on both BSA and CrCL increased drug exposure in younger patients. A dosing algorithm based on BSA and CrCL should be tested in future studies.

\author{
M.D. Pescovitz ${ }^{1}$, R.B. Ettenger ${ }^{2}$, C.F. Strife ${ }^{3}$, \\ J.R. Sherbotie ${ }^{4}$, S.E. Thomas ${ }^{5}$, \\ S. McDiarmid ${ }^{2}$, S. Bartosh ${ }^{6}$, J. Ives $^{7}$, \\ M.R. Bouw ${ }^{7}$, J. Bucuvalas ${ }^{8}$ \\ ${ }^{1}$ Departments of Surgery and Microbiology/lmmunology, \\ Indiana University, Indianapolis, Indiana, USA, ${ }^{2}$ Division of \\ Pediatric Nephrology, UCLA Medical Center, Los Angeles, \\ California, USA, ${ }^{3}$ Division of Nephrology and Hypertension, \\ Cincinnati Children's Hospital Medical Center, Cincinnati, \\ Ohio, USA, ${ }^{4}$ Pediatric Nephrology and Hypertension, \\ University of Utah School of Medicine, Salt Lake City, Utah, \\ USA, ${ }^{5}$ Pediatric Nephrology, C.S. Mott Children's Hospital, \\ University of Michigan Medical Center, Ann Arbor, Michigan, \\ USA, ${ }^{6}$ Department of Pediatrics, University of Wisconsin \\ Medical School, Madison, Wisconsin, USA, ${ }^{7}$ Roche Products \\ Ltd, Welwyn Garden City, Herts, UK, ${ }^{8}$ Pediatric Liver Care \\ Center, Cincinnati Children's Hospital, Cincinnati, Ohio, USA
}

Key words: valganciclovir; ganciclovir; kidney transplant; liver transplant; pediatric; pharmacokinetics

\author{
Correspondence to: \\ Dr. Mark Pescovitz, Indiana University, Department of Surgery, \\ MS2031, 635 Barnhill Dr., Indianapolis, IN 46202-5124, USA \\ Tel: +13172741010 \\ Fax: + 13172780264 \\ E-mail: mpescov@iupui.edu
}

Received 11 March 2009, revised 11 June 2009, 6 September 2009, accepted for publication 12 September 2009

DOI: 10.1111/j.1399-3062.2009.00478.x

Transpl Infect Dis 2010: 12: 195-203
Cytomegalovirus (CMV) is a major cause of morbidity and mortality in children after solid organ transplantation (SOT) (1), because many of them are likely to be CMV seronegative at the time of transplantation. While the efficacy of ganciclovir $(\mathrm{GCV})$ for the prevention and treatment of $\mathrm{CMV}$ in SOT recipients is well established in adults (2-4), its use in the management of CMV disease is limited by poor oral (p.o.) bioavailability (5), and thus the need for long-term intravenous (IV) administration.

Valganciclovir, the valine ester of $\mathrm{GCV}$, overcomes the limitations of p.o. GCV and is a convenient alternative to IVadministration. The 10 -fold higher absolute bioavailability of p.o. valganciclovir compared with $\operatorname{GCV}(5,6)$, means that, in adults, dosing with p.o. valganciclovir $900 \mathrm{mg}$ once daily provides similar GCV exposure to IV GCV $(5 \mathrm{mg} / \mathrm{kg} /$ day) (7). However, dosing with valganciclovir tablets may not be appropriate in some patients because of their inability to swallow solids for a variety of reasons. To this end, a p.o. valganciclovir solution has been developed to accommodate these patients that is bioequivalent to the tablet formulation and with a similar safety profile, thus allowing the 2 p.o. formulations to be interchangeable (8).

No universal rule exists for converting adult drug doses to doses for children (9). Adjusting according to body weight or body surface area (BSA) is not always successful $(10,11)$. Furthermore, a p.o. solution of valganciclovir would 
also be useful for children unable to swallow tablets or capsules. To fill in this knowledge gap, we designed and conducted 2 independent studies of p.o. valganciclovir solution and IV GCV in de novo pediatric kidney or liver transplant recipients. We hypothesized that IV dosing of GCV and p.o. dosing of valganciclovir, normalized for BSA in pediatric liver and kidney transplant patients, would provide similar GCV area under the curve (AUC) values as those established for adults. Additionally, we hypothesized that BSA-normalized p.o. valganciclovir doses would provided comparable GCV AUC values to BSA-normalized IV GCV doses in this population.

\section{Methods}

\section{Study design and patient population}

Two open-label studies were conducted in 9 US centers (6 renal and 3 liver). Both studies were approved by the Institutional Review Boards at each institution and written informed consent was provided by patients' parents or guardians and assent by the children as appropriate.

\section{Renal study}

Children aged 3 months to 16 years considered at risk of developing CMV disease who had received their first kidneyonly transplant were eligible for study entry. Patients were required to have absolute neutrophil count $>1000$ cells $/ \mu \mathrm{L}$; platelet count $>25,000$ cells $/ \mu \mathrm{L}$; hemoglobin $>8.0 \mathrm{~g} / \mathrm{dL}$; and stable renal function with creatinine clearance (CrCL) $>45 \mathrm{~mL} / \mathrm{min} / 1.73 \mathrm{~m}^{2}$ (Schwartz et al. formula [12]). Exclusion criteria included allergic or other significant adverse reaction to acyclovir, GCV, or valacyclovir; severe, uncontrolled diarrhea or evidence of malabsorption; patients simultaneously participating in another trial, except as approved by the sponsor; female patients who were lactating and would not discontinue nursing before study entry; pregnancy; and liver function impairment of $>5$ times the upper limit of normal for aspartate aminotransferase (AST) or alanine aminotransferase (ALT).

\section{Liver study}

The criteria for the liver trial were identical to those of the renal study, with the exception that children at risk of contracting Epstein-Barr virus (EBV) could also be included. Exclusion criteria were also identical, except for the exclusion of liver function impairment and the inclusion of evidence of graft rejection or antiviral prophylaxis with a treatment other than IV GCV between transplant and enrollment.

\section{Calculation of dosage}

According to BSA

Reference doses were based on adult dosages as follows. The standard $5 \mathrm{mg} / \mathrm{kg}$ IV GCV dose for a $70 \mathrm{~kg}$ adult with a BSA of $1.73 \mathrm{~m}^{2}$ is $350 \mathrm{mg}$; this corresponds to a pediatric reference dose of $200 \mathrm{mg} / \mathrm{m}^{2}$. The standard $900 \mathrm{mg}$ dose of p.o. valganciclovir for an adult with BSA of $1.73 \mathrm{~m}^{2}$ corresponds to a pediatric reference dose of $520 \mathrm{mg} / \mathrm{m}^{2}$.

In both studies, IV GCV and p.o. valganciclovir dosages were calculated as follows:

$$
\begin{aligned}
\text { Full dose }(\mathrm{mg})= & \text { Reference } \operatorname{dose}\left(\mathrm{mg} / \mathrm{m}^{2}\right) \\
& \times \text { BSA of patient }\left(\mathrm{m}^{2}\right),
\end{aligned}
$$

where BSA was calculated using Mosteller's equation (13):

$$
\operatorname{BSA}\left(\mathrm{m}^{2}\right)=\sqrt{ }[(\text { height }(\mathrm{cm}) \times \text { weight }(\mathrm{kg})) / 3600] .
$$

In order to estimate the most appropriate dose of p.o. valganciclovir in children an additional dose level of p.o. valganciclovir $\left(260 \mathrm{mg} / \mathrm{m}^{2}\right)$ corresponding to $50 \%$ of the reference p.o. valganciclovir dose was included in the renal study.

According to renal function

In both studies, the reference doses for both agents were adjusted for reduced renal function based on estimated $\mathrm{CrCL}$, as outlined in Table 1. CrCL was estimated from serum creatinine using the Schwartz et al. formula (12):

$$
\begin{aligned}
\mathrm{CrCL}\left(\mathrm{mL} / \mathrm{min} / 1.73 \mathrm{~m}^{2}\right)= & {[k \times \text { height }(\mathrm{cm})] / } \\
& {[\text { serum creatinine }(\mathrm{mg} / \mathrm{dL})], }
\end{aligned}
$$

where $k=0.45$ for those aged $<2$ years, $k=0.55$ for those aged $\geq 2$ years to $<13$ years, and for those aged $\geq 13$ years to $\leq 20$ years, $k=0.7$ for males and $k=0.55$ for females.

\section{Drug regimens and procedures}

Renal study

Individual study drug dosing lasted for a total of 4 days. The shorter interval in the renal study compared with the 14 days in the liver study, resulted from the more rapid time to stability and discharge from the hospital for the renal transplant patients. Screening assessments were performed in the first week after transplantation after the stabilization of renal function, followed by 4 consecutive days of treatment with study drugs, a follow-up visit (day of last pharmacokinetic sample, 28-32 days post transplant), and a safety review visit (28 days after cessation of study drug \pm 4 days). Serum creatinine used to estimate $\mathrm{CrCL}$ was measured on each day of treatment and at the follow-up visit. After stabilization of renal function following transplantation, subjects received treatment once daily between 


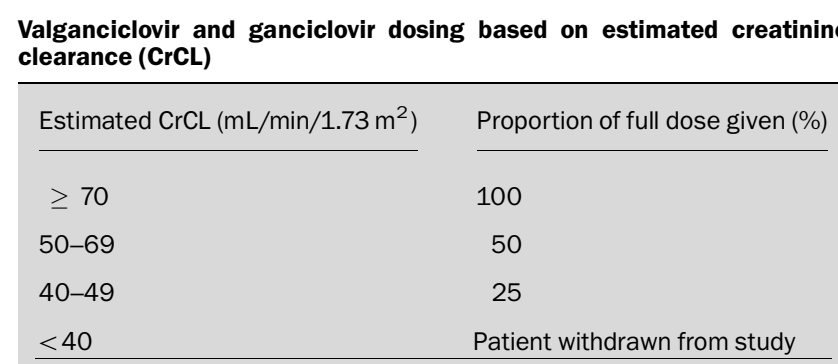

Reference doses were $200 \mathrm{mg} / \mathrm{m}^{2}$ for intravenous ganciclovir and 260 or $520 \mathrm{mg} / \mathrm{m}^{2}$ for oral valganciclovir solution.

Table 1

7 and 9 a.m. with a single dose of IV GCV on days 1 and 2 and a single dose of p.o. valganciclovir solution of $260 \mathrm{mg} /$ $\mathrm{m}^{2}$ on day 3 and $520 \mathrm{mg} / \mathrm{m}^{2}$ on day 4 . Blood samples for determination of GCV concentrations were collected on dosing-days 2, 3, and 4 as follows: pre-dose (up to $2 \mathrm{~h}$ before dosing), and $1 \mathrm{~h}$ (immediately before the end of the infusion), and between $2-3,5-7$, and $10-12 \mathrm{~h}$ post dose on day 2 ; pre-dose, and between $0.25-0.75,1-3,5-7$, and $10-12 \mathrm{~h}$ post dose on day 3; and pre-dose, and between $0.25-0.75$, $1-3,5-7,10-12$, and $22-24$ h post dose on day 4 .

Liver study

Screening and enrollment were conducted between days 1 and 4 (day 0 was the day of the transplant); patients received study drugs from enrollment up to day 14 post transplant. The follow-up and safety reviews were on days 28-32 and $42 \pm 4$ post treatment, respectively. Serum creatinine used to estimate $\mathrm{CrCL}$ was measured on days $11-14$. Study drugs were administered twice daily - between 7 and 9 a.m. for the first dose, and the second as close as possible to $12 \mathrm{~h}$ after the first dose. However, the AUC was calculated using only samples obtained during the 12 -h period around the morning dose of drug. The 24 -h AUC was calculated using non-linear mixed effect modeling (NONMEM) assuming once a day dosing.

Patients received treatment with IV GCV, initiated on enrollment (days 1-4 after transplantation) and continued to day 12 post transplant. On days 13 and 14 post transplant, patients received p.o. valganciclovir solution twice daily. Blood sampling was conducted on days 12 and 14 as follows: pre-dose (up to $2 \mathrm{~h}$ before dosing), and $1 \mathrm{~h}$ (immediately before the end of the infusion), and between $2-3,5-7$, and $10-12 \mathrm{~h}$ post dose on day 12 ; and pre-dose, and between $0.25-0.75,1-3,5-7$, and $10-12 \mathrm{~h}$ post dose on day 14 .

\section{Drug administration}

In both studies, IV GCV was given over $1 \mathrm{~h}$ as a constant rate infusion. GCV for IV infusion (Cytovene ${ }^{\circledR}$, Roche, Nutley, New Jersey, USA) was provided as sterile, lyophilized powder in sealed vials containing $500 \mathrm{mg} \mathrm{GCV}$ for reconstitution in $10 \mathrm{~mL}$ of saline. Valganciclovir was provided as a strawberryflavored $15 \mathrm{~g}$ powder blend containing $3 \mathrm{~g}$ valganciclovir; it was reconstituted with $50 \mathrm{~mL}$ water to give a final volume of $60 \mathrm{~mL}$; the solution was sweetened with saccharine and was administered within 15 min of a meal. One batch of valganciclovir p.o. solution was used in each study.

\section{Study assessments and procedures}

Screening assessment in both studies included a limited physical examination, laboratory safety tests (hematology, serum chemistry), and a medical examination including assessment of concomitant illnesses, laboratory safety tests, assessment of puberty stage (Tanner stage [14]), pregnancy tests for females of child-bearing potential, measurement of serum creatinine, and estimated CrCL. In addition, the CMV serological status of the graft and recipient was determined in the renal study, and the CMV and EBV serological status of the graft and recipient was determined in the liver study.

Adverse events occurring since consent and medications to treat these adverse events were also recorded in both studies.

\section{Drug assay}

In each study, venous blood $(1 \mathrm{~mL})$ was collected into plastic ethylene diamine tetraacetic acid tubes and centrifuged $(15 \mathrm{~min}$ at $1200 \times g)$ at $4^{\circ} \mathrm{C}$ within $30 \mathrm{~min}$. Plasma samples were frozen immediately at $-70^{\circ} \mathrm{C}$ pending analysis. The plasma concentration of GCV was determined by Analytico Medinet (Breda, the Netherlands) following deproteination, by adding trichloroacetic acid, using a validated specific liquid chromatography-tandem mass spectrometry method. GCV was provided by Hoffmann La-Roche (Basel, Switzerland). The dynamic range for the quantification of GCV was between 0.040 and $20 \mu \mathrm{g} / \mathrm{mL}$, which was based on 8 different concentration levels (coefficient of correlation $\geq 0.99$. The overall accuracy and inter-assay variability of the assay was $98.7-105 \%$ and $0.7-12.0 \%$, respectively.

Because of the rapid conversion of valganciclovir to GCV, plasma valganciclovir concentrations are not detectable, and were therefore not measured in either study or included in the pharmacokinetic model.

\section{Population pharmacokinetic modeling}

Pharmacokinetic model

A 2-compartmental model for GCV was considered appropriate based on previous population pharmacokinetic analyses for GCV in adult SOT recipients (7). The model 
parameters were clearance $(\mathrm{CL})$, volume of distribution at steady state $\left(V_{\mathrm{ss}}\right)$, intercompartmental clearance $(Q)$, peripheral volume of distribution $\left(V_{\text {periph }}\right)$, first-order absorption (for valganciclovir), lag time, and bioavailability of GCV from valganciclovir (F1).

NONMEM software (Version V, Icon, Dublin, Ireland) and the first-order estimation method were used. NONMEM was developed at the University of California, San Francisco as software for fitting non-linear mixed effects (statistical regression-type) models. The methodology is particularly useful for population pharmacokinetic analyses and in situations such as in this trial, where there are few pharmacokinetic samples per subject. Inter-subject variability was assessed using an exponential function. A combined multiplicative and additive error model was used for the residual random effects.

Covariate selection was conducted on gender, age, height, puberty, body weight, BSA, type of SOT (kidney or liver), serum creatinine, AST, ALT, total bilirubin, and CrCL derived from the Cockroft-Gault formula (CrCLC) (15) and Schwartz et al. formula (CrCLS) (11). Stepwise generalized additive modeling in Xpose 3.102 was used initially to select the covariates to be tested within NONMEM. Then a comprehensive forward addition and backward procedure was followed to build the final covariate model. Model discrimination was based on a decrease in objective function values and visual inspection of goodness-of-fit plots.

\section{Pharmacokinetic endpoints}

The primary pharmacokinetic parameter in both studies was the extent of exposure (AUC) to GCV after administration of IV GCV and p.o. valganciclovir solution, determined as the area under the GCV concentration-time curve over $24 \mathrm{~h}\left(\mathrm{AUC}_{0-24}\right)$ using population pharmacokinetic analysis. Population pharmacokinetic analysis was also used to determine secondary pharmacokinetic parameters, which included CL; F1; $V_{\mathrm{ss}} ; V_{\text {periph}}$; volume of central compartment $\left(V_{\text {cent }}\right)$; absorption rate constant $\left(K_{\mathrm{a}}\right)$; maximum plasma concentration $\left(C_{\max }\right)$; and terminal elimination half-life $\left(t_{1 / 2}\right)$. Individual parameters were calculated using individual post hoc estimates derived from population estimates and the individual data.

\section{Statistics}

No formal statistical tests or sample size calculations were performed. The planned target recruitment was 24 patients in the renal study and 20 patients in the liver study. These sample sizes were deemed adequate to derive the pharmacokinetic profile of GCV after administration of IV GCV and p.o. valganciclovir solution. Descriptive statistics were used to summarize the pharmacokinetic data.

\section{Results}

\section{Renal study}

Twenty-six patients were enrolled, aged $\leq 5$ years $(n=5)$, 6 -11 years $(n=7)$, and $12-16$ years $(n=14)$ (Table 2$)$. One patient withdrew prematurely after refusing treatment with valganciclovir p.o. solution, having received both doses of IV GCV. Data for this patient are included in all but the pharmacokinetic analyses. Two patients had their dose of study medication reduced because of poor renal function. The first patient (13 years old) received $25 \%$ of

\section{Demographics and baseline characteristics of patient population}

\begin{tabular}{|c|c|c|}
\hline Variable & Renal study $(n=26)$ & Liver study $(n=20)$ \\
\hline Male, $n(\%)$ & $17(65)$ & $11(55)$ \\
\hline \multicolumn{3}{|l|}{ Race, $n(\%)$} \\
\hline Caucasian & $13(50)$ & $18(90)$ \\
\hline Black & $5(19)$ & $2(10)$ \\
\hline Oriental & - & - \\
\hline Other & $8(31)$ & - \\
\hline $\begin{array}{l}\text { Median age (range) } \\
\text { (years) }\end{array}$ & $12(1-16)$ & $2(0-16)$ \\
\hline $\begin{array}{l}\text { Median weight (range) } \\
\text { (kg) }\end{array}$ & $32.4(10.6-81.6)$ & $11.9(5.7-56.9)$ \\
\hline $\begin{array}{l}\text { Median height (range) } \\
(\mathrm{cm})\end{array}$ & $137.0(74.0-185.0)$ & $82.5(59-175)$ \\
\hline $\begin{array}{l}\text { Mean estimated } \mathrm{CrCL} \\
(\mathrm{SD})(\mathrm{mL} / \mathrm{min})\end{array}$ & $109.9(43.6)$ & $153.4(75.3)$ \\
\hline \multicolumn{3}{|l|}{ CMV status, $n(\%)^{1}$} \\
\hline $\mathrm{D}+/ \mathrm{R}+$ & $16(62)$ & $4(20)$ \\
\hline $\mathrm{D}+/ \mathrm{R}-$ & $6(23)$ & $6(30)$ \\
\hline$D-/ R+$ & $2(8)$ & $2(10)$ \\
\hline $\mathrm{D}-/ \mathrm{R}-$ & $2(8)$ & $8(40)$ \\
\hline \multicolumn{3}{|l|}{ EBV status, $n(\%)^{1,2}$} \\
\hline $\mathrm{D}+/ \mathrm{R}+$ & & $5(25)$ \\
\hline $\mathrm{D}+/ \mathrm{R}-$ & & $6(30)$ \\
\hline $\mathrm{D}-/ \mathrm{R}+$ & & $2(10)$ \\
\hline$D-/ R-$ & & $6(30)$ \\
\hline $\mathrm{D}_{\mathrm{ND}} / \mathrm{R}+$ & & $1(5)$ \\
\hline \multicolumn{3}{|c|}{$\begin{array}{l}{ }^{1} \text { Enrollment of patients who were donor seronegative/recipient } \\
\text { seronegative for } \mathrm{CMV} \text { and/or EBV was permitted because all pediatric } \\
\text { patients were considered at risk, regardless of their serotype. } \\
{ }^{2} \text { EBV serological status not determined in study in renal transplant } \\
\text { recipients. } \\
\text { CMV, cytomegalovirus; CrCL, creatinine clearance; D +, donor } \\
\text { seropositive; D -, donor seronegative; EBV, Epstein-Barr virus; } \\
\mathrm{R}+\text {, recipient seropositive; } \mathrm{R}-\text {, recipient seronegative; SD, standard } \\
\text { deviation; ND, not determined. }\end{array}$} \\
\hline
\end{tabular}

Table 2 
the BSA-adjusted dose of $200 \mathrm{mg} / \mathrm{m}^{2}$ of IV GCVand $50 \%$ of the BSA-adjusted higher dose of p.o. valganciclovir solution $\left(520 \mathrm{mg} / \mathrm{m}^{2}\right)$. The second patient (12 years old) received $50 \%$ of the BSA-adjusted dose of $200 \mathrm{mg} / \mathrm{m}^{2}$ of IV GCV.

\section{Liver study}

In the liver study, 20 patients were enrolled: aged $\leq 5$ years $(n=15), 6-11$ years $(n=2)$, and $12-16$ years $(n=3)$ (Table 2). One patient with renal function slightly outside of the $45 \mathrm{~mL} / \mathrm{min} / 1.73 / \mathrm{m}^{2}$ inclusion criteria $(\mathrm{CrCL}=41.7 \mathrm{~mL} /$ $\min / 1.73 \mathrm{~m}^{2}$ ) was inadvertently entered into the study; the subject's data were included in the analyses. Fifteen patients completed the study. Five of the 20 patients (all aged $<5$ years) were withdrawn.

\section{Pharmacokinetic results}

Final pharmacokinetic model (combined patient cohort)

Of the 46 patients enrolled, 43 were included in the pharmacokinetic model. One patient from the renal study was excluded from the pharmacokinetic model because plasma levels were not recorded. Two patients from the liver study were withdrawn before receiving study drug and were also excluded from the pharmacokinetic model. Three other liver transplant subjects did not complete the entire study but had sufficient data to include in the pharmacokinetic analysis. Of the 43 patients included in the model, data were included from a liver transplant recipient for whom GCV plasma concentrations only after administration of IV GCV were available because this patient was withdrawn before p.o. valganciclovir administration, and from another liver transplant recipient who received p.o. valganciclovir for only 1 day.

The final model for GCV plasma concentrations was a 2compartmental model with first-order formation for p.o. valganciclovir, lag time, and relative bioavailability. Intersubject random variability was modeled for $K_{\mathrm{a}}, \mathrm{CL}, V_{\mathrm{ss}}, \mathrm{Q}$, and $\mathrm{F} 1$ as exponential errors. The residual error consisted of a multiplicative and an additive error arm. The multiplicative error was $29 \%$ and the additive error was $0.14 \mathrm{ng} /$ $\mathrm{mL}$, which is about 3 -fold above the lower limit of quantification $(0.04 \mathrm{ng} / \mathrm{mL})$. The population pharmacokinetic parameters of the final model are presented in Table 3. The height of the patient and CrCLC were identified as statistically significant covariates for $\mathrm{CL}, V_{\mathrm{ss}}$, and $V_{\text {periph }}$. Neither age, gender, nor type of organ were significant covariates in this model. Inspection of the goodness-of-fit plots did not show any substantial bias thus indicating that the pharmacokinetic parameters were well estimated. There was no clinically relevant difference in covariate selection between using the Schwartz and Cockcroft Gault formulae for calculation of CrCL (Roche data on file).

\section{Individual pharmacokinetic parameters}

Summaries of the derived and individual estimated parameters from both studies are shown in Tables 4 and 5 , respectively. $\mathrm{AUC}_{0-24}$ and $C_{\max }$ were calculated for the doses of $200 \mathrm{mg} / \mathrm{m}^{2}$ for IV GCV and $520 \mathrm{mg} / \mathrm{m}^{2}$ for p.o. valganciclovir solution. Two subjects had their doses decreased per the dosing algorithm (Table 1) and are included in this analysis. The first received $25 \%$ of the BSA-adjusted dose of $200 \mathrm{mg} / \mathrm{m}^{2} \mathrm{IV} \mathrm{GCV}$, resulting in an exposure to GCV of $22.96 \mathrm{mg} \cdot \mathrm{h} / \mathrm{L}$, This subject also received $50 \%$ of the BSA-adjusted higher dose of p.o. valganciclovir syrup resulting in a GCV exposure of $58.35 \mathrm{mg} \cdot \mathrm{h} / \mathrm{L}$. The second subject received $50 \%$ of the BSA-adjusted dose of $200 \mathrm{mg} / \mathrm{m}^{2}$ of IV GCV, which resulted in a GCVexposure of $57.36 \mathrm{mg} \cdot \mathrm{h} / \mathrm{L}$.

It was shown during modeling that pharmacokinetic values for the lower dose of $260 \mathrm{mg} / \mathrm{m}^{2}$ of p.o. valganciclovir solution investigated in the renal study would be half of those shown in Table 4 for the $520 \mathrm{mg} / \mathrm{m}^{2}$ dose due to linearity in the pharmacokinetics of valganciclovir.

Basic pharmacokinetic (PK) parameters of ganciclovir of the combined final population PK model

\begin{tabular}{|c|c|c|c|c|}
\hline Description & PK parameter & Estimate & Standard error of estimate & Intersubject CV (\%) \\
\hline Absorption constant & $K_{\mathrm{a}}(\mathrm{h})$ & 0.42 & 0.066 & 16 \\
\hline Bioavailability & $\mathrm{F} 1$ & 0.55 & 0.038 & 6.9 \\
\hline Lag time & $T_{\text {lag }}(\mathrm{h})$ & 0.22 & 0.0096 & 4.4 \\
\hline Clearance & $\mathrm{CL}(\mathrm{L} / \mathrm{h})$ & 5.4 & 0.29 & 5.4 \\
\hline Volume of distribution at steady state & $V_{\mathrm{ss}}(\mathrm{L})$ & 20 & 1.2 & 6 \\
\hline Peripheral volume & $V_{\text {periph }}(\mathrm{L})$ & 15 & 1 & 6.7 \\
\hline Intercompartment clearance & $Q(L / h)$ & 8 & 1.5 & 19 \\
\hline Multiple error & & 0.29 & 0.034 & 12 \\
\hline Additive error $(\mathrm{ng} / \mathrm{mL})$ & & 0.14 & 0.046 & 33 \\
\hline
\end{tabular}

Table 3 
Derived pharmacokinetic parameters ${ }^{1}$ of ganciclovir in pediatric renal or liver transplant recipients following treatment with oral valganciclovir and intravenous ganciclovir, by age group

\begin{tabular}{|c|c|c|c|c|c|c|}
\hline \multirow[b]{2}{*}{ Age group } & \multicolumn{3}{|c|}{ Intravenous ganciclovir ( $200 \mathrm{mg} / \mathrm{m}^{2}$ ) } & \multicolumn{3}{|c|}{ Oral valganciclovir ( $520 \mathrm{mg} / \mathrm{m}^{2}$ ) } \\
\hline & $0-5$ years & $6-11$ years & $12-16$ years & $0-5$ years & $6-11$ years & $12-16$ years \\
\hline Renal study & $n=4$ & $n=7$ & $n=14$ & $n=4$ & $n=7$ & $n=14$ \\
\hline $\begin{array}{l}\mathrm{AUC}_{\mathrm{O}-24} \\
(\mathrm{mg} \cdot \mathrm{h} / \mathrm{L})\end{array}$ & $\begin{array}{l}22.18 \\
(17.13-27.1)\end{array}$ & $\begin{array}{l}37.86 \\
(15.78-43.59)\end{array}$ & $\begin{array}{l}38.58 \\
(21.01-89.29)\end{array}$ & $\begin{array}{l}22.22 \\
(16.15-24.52)\end{array}$ & $\begin{array}{l}43.78 \\
(14.45-55.07)\end{array}$ & $\begin{array}{l}39.88 \\
(20.95-70.64)\end{array}$ \\
\hline$C_{\max }(\mathrm{mg} / \mathrm{mL})$ & $\begin{array}{l}10.19 \\
(9.17-12.29)\end{array}$ & $\begin{array}{l}9.03 \\
(6.79-11.28)\end{array}$ & $\begin{array}{l}9.40 \\
(3.51-25.26)\end{array}$ & $\begin{array}{l}5.10 \\
(4.20-8.50)\end{array}$ & $\begin{array}{l}6.01 \\
(3.37-9.08)\end{array}$ & $\begin{array}{l}5.40 \\
(3.56-7.92)\end{array}$ \\
\hline Liver study & $n=13$ & $n=2$ & $n=3$ & $n=13$ & $n=2$ & $n=3$ \\
\hline $\begin{array}{l}\mathrm{AUC}_{\mathrm{O}-24} \\
(\mathrm{mg} \cdot \mathrm{h} / \mathrm{L})\end{array}$ & $\begin{array}{l}24.3 \\
(14.1-38.9)\end{array}$ & $\begin{array}{l}35.2 \\
(27.1-43.2)\end{array}$ & $\begin{array}{l}23.4 \\
(19.2-25.8)\end{array}$ & $\begin{array}{l}23.4 \\
(11.8-40.6)\end{array}$ & $\begin{array}{l}46.8 \\
(35.2-58.4)\end{array}$ & $\begin{array}{l}25.8 \\
(25-30.9)\end{array}$ \\
\hline$C_{\max }(\mathrm{mg} / \mathrm{L})$ & $\begin{array}{l}12.2 \\
(9.17-15)\end{array}$ & $\begin{array}{l}9.29 \\
(4.73-13.9)\end{array}$ & $\begin{array}{l}11.8 \\
(11.6-12.4)\end{array}$ & $\begin{array}{l}5.51 \\
(2.72-7.18)\end{array}$ & $\begin{array}{l}5.29 \\
(3.79-6.79)\end{array}$ & $\begin{array}{l}6.9 \\
(5.59-7.04)\end{array}$ \\
\hline
\end{tabular}

${ }^{1}$ Values are expressed as medians (range).

$\mathrm{AUC}_{0-24}$, area under the concentration time curve from 0 to $24 \mathrm{~h} ; C_{\max }$, maximum plasma concentration.

\section{Table 4}

Across both studies, exposure to GCV was noticeably low in very young patients (aged $\leq 5$ years) for both IV GCV and the p.o. valganciclovir solution (Table 4). In addition, in all age groups, exposure to GCV following treatment with IV GCV was broadly similar to that following treat- ment with p.o. valganciclovir solution $520 \mathrm{mg} / \mathrm{m}^{2}$. In both liver and kidney, $C_{\max }$ values for all ages were comparable, with means ranging $9.03-12.2 C_{\max }$. Values were notably lower for p.o. valganciclovir, but also comparable between age groups/transplant types with means of 5.10-6.9.

Individual estimated pharmacokinetic parameters ${ }^{1}$ of ganciclovir in pediatric renal or liver transplant recipients by age group

\begin{tabular}{|c|c|c|c|}
\hline \multirow[b]{3}{*}{ Renal study } & \multicolumn{3}{|l|}{ Age group (years) } \\
\hline & $0-5$ & $6-11$ & $12-16$ \\
\hline & $n=4$ & $n=7$ & $n=14$ \\
\hline $\mathrm{CL}(\mathrm{L} / \mathrm{h})$ & $4.71(3.83-5.23)$ & $4.92(3.62-8.75)$ & 7.40 (3.39-12.93) \\
\hline $\mathrm{F} 1$ & $0.44(0.40-0.59)$ & $0.54(0.46-0.80)$ & $0.53(0.42-0.77)$ \\
\hline$K_{a}(\mathrm{~L} / \mathrm{h})$ & $0.80(0.63-1.92)$ & $0.67(0.42-1.18)$ & $0.72(0.16-1.88)$ \\
\hline$V_{\text {cent }}(\mathrm{L})$ & $7.20(3.99-7.74)$ & $15.03(10.87-17.81)$ & $22.07(9.58-34.83)$ \\
\hline$V_{\text {periph }}(\mathrm{L})$ & $5.71(2.13-10.12)$ & $9.94(6.91-47.20)$ & $18.84(5.10-144.30)$ \\
\hline$V_{\mathrm{ss}}(\mathrm{L})$ & $13.19(6.11-17.29)$ & $24.99(17.77-64.42)$ & 40.81 (17.85-177.90) \\
\hline Liver study & $n=13$ & $n=2$ & $n=3$ \\
\hline $\mathrm{CL}(\mathrm{L} / \mathrm{h})$ & $4.05(2.11-7.92)$ & $2.86(1.88-3.84)$ & $15.1(11.4-16.8)$ \\
\hline $\mathrm{F} 1$ & $0.52(0.39-0.83)$ & $0.71(0.7-0.72)$ & $0.64(0.57-0.72)$ \\
\hline$K_{a}(\mathrm{~L} / \mathrm{h})$ & $0.45(0.13-0.86)$ & $0.35(0.23-0.48)$ & $0.42(0.3-0.52)$ \\
\hline$V_{\text {cent }}(\mathrm{L})$ & $1.66(0.45-2.51)$ & $5.74(5-6.48)$ & $12.8(12.8-16.8)$ \\
\hline$V_{\text {periph }}(\mathrm{L})$ & $5.65(2.9-7.6)$ & $14.6(12-17.3)$ & $30.7(25.1-34.6)$ \\
\hline$V_{\text {ss }}(\mathrm{L})$ & $7.62(3.35-10.1)$ & $20.4(17-23.8)$ & $43.5(37.9-51.4)$ \\
\hline
\end{tabular}

Table 5 
In the renal study, CL increased with age, as did drug exposure. Moreover, GCVexposure based on BSA alone in the renal study was generally lower in younger children, but was increased when corrected for both BSA and renal function (Fig. 1). The very low $r$ value, when adjusting by both $\mathrm{BSA}$ and $\mathrm{CrCl}$, indicates that $\mathrm{AUC}$ is no longer correlated with age, an important improvement in a dosing regimen. In contrast, in the liver study, there was no clear pattern in the age-related effect on clearance or exposure of GCV.This could be, in part, attributed to the skewed distribution of patients across the age groups in the liver study. In this study, the clearance of GCV was markedly lower in the 13 children aged $\leq 5$ years than the 3 children aged $12-16$ years; however, it was lower still in the 2 children aged 6-11 years (Table 5 ). The $t_{1 / 2}$ was shorter in younger children (median $1.65 \mathrm{~h}$ ) than in those aged $6-11$ and 12-16 years (6.80 and $4.35 \mathrm{~h}$, respectively). Similarly, in the renal study, $t_{1 / 2}$ increased with increasing age; median values were 3.28 (range 1.97-6.31), 4.41 (range 3.06-12.77), and 5.62 (3.32-27.04) in the $0-5,6-11$, and $12-16$ years age groups, respectively.

The estimated bioavailability of GCV from p.o. valganciclovir solution was only slightly lower in the younger children than the older children in both studies (Table 5); this suggests that there was essentially no dependence of F1 values on age.

\section{Safety}

In both studies, IV GCV and valganciclovir p.o. solution were generally well tolerated. The majority of treatmentemergent adverse events were of mild or moderate severity and were gastrointestinal in nature. There were no deaths in either study.

\section{Renal study}

Treatment-emergent adverse events were reported in $50 \%$ of patients in the IV GCV phase and in $32 \%$ of patients in the p.o. valganciclovir phase. Four patients experienced treatment-related adverse events; 3 while receiving p.o. valganciclovir solution (nausea $n=1$, vomiting $n=1$, and headache $n=2$ ), and 1 while receiving IV GCV (thrombocytopenia). Four severe adverse events were reported, of which 1 occurred on treatment (sepsis; with valganciclovir solution). Four patients experienced 6 serious adverse events, of which 2 occurred on treatment with p.o. valganciclovir but were not considered treatment related.

\section{Liver study}

Treatment-emergent adverse events were reported in $90 \%$ of patients in the IV GCV phase of the study. There were only 2 adverse events in the p.o. valganciclovir treatment phase, which were not severe, serious, or treatment related. Three
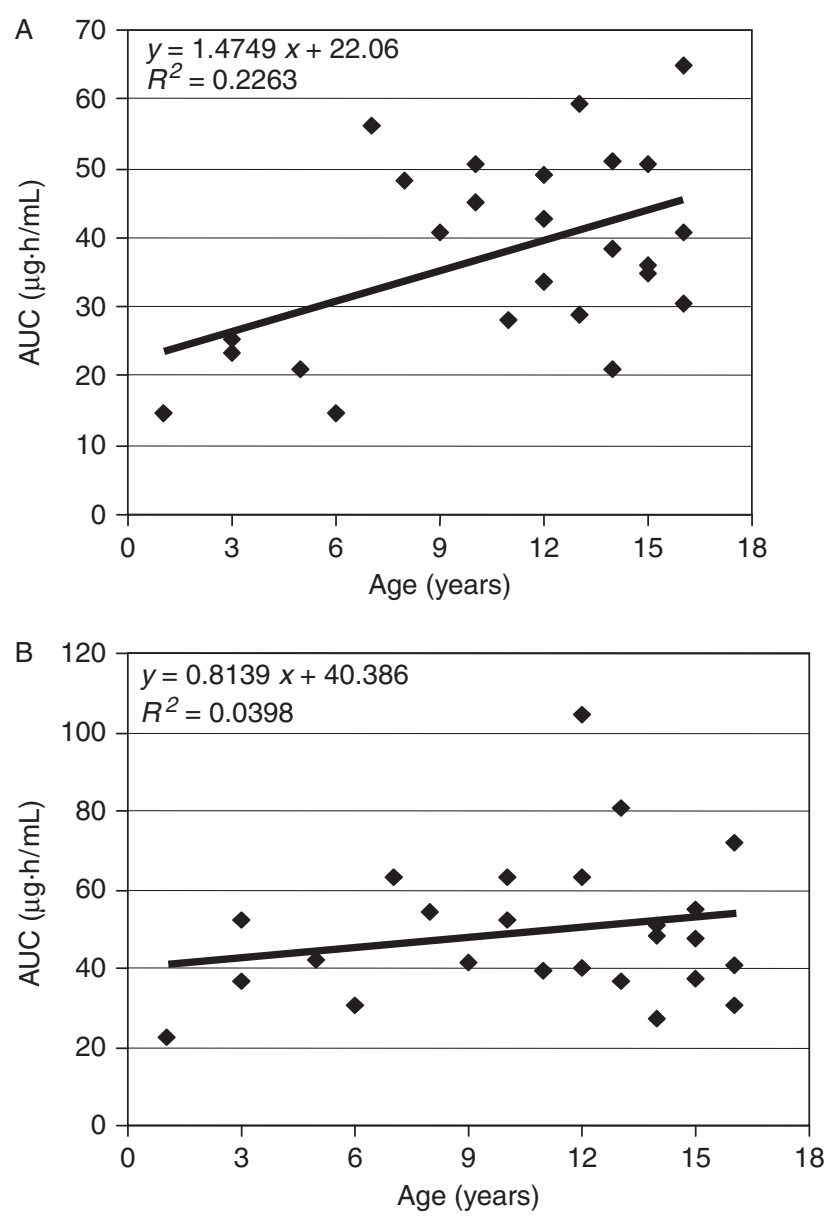

Fig. 1. Relationship between age and projected ganciclovir exposure from oral valganciclovir in patients receiving a renal transplant. Patients were dosed with study drug according to an algorithm based on (A) body surface area, and (B) body surface area and renal function.

patients experienced a total of 6 adverse events that were remotely or possibly related to treatment with IV GCV (rash in 1 patient, anemia and renal impairment in 1 patient, and vomiting, diarrhea, and increased hepatic enzymes in 1 patient). Of 22 severe adverse events, 2 were life threatening (2 occurrences of post-procedural hemorrhage in 1 patient during IV GCV treatment and during the off-treatment phase of the study). Ten patients experienced 14 serious adverse events in the IV GCV phase, of which 2 were related to study treatment (vomiting and increased hepatic enzymes).

\section{Discussion}

The median exposure to GCV in older children receiving $520 \mathrm{mg} / \mathrm{m}^{2}$ p.o. valganciclovir solution $(39.88 \mathrm{mg} \cdot \mathrm{h} / \mathrm{L}$ in $12-16$-year-olds in the renal study) was in agreement with 
that observed in adult patients receiving $900 \mathrm{mg}$ valganciclovir once daily (mean of approximately $46 \mathrm{mg} \cdot \mathrm{h} /$ $\mathrm{mL})(5,7)$. In the renal study, the GCV exposure, based on BSA alone, was generally low in younger children; drug exposure was increased in this age group when corrected for both BSA and renal function (estimated via $\mathrm{CrCL}$ ). The clear trend of decreasing exposure with younger age shown in the renal study was not observed in the liver study, presumably because there were limited number of patients in the 2 older liver transplant groups. The youngest children were underexposed to GCV by about 2 -fold; this did not appear to be attributable to a lack of simultaneous adjustment for age in clearance because clearance of GCV was lower in the youngest age groups compared with the oldest age groups (median $4.7 \mathrm{~L} / \mathrm{h}$ in $0-5$-year-olds vs. $7.4 \mathrm{~L} / \mathrm{h}$ in $12-$ 16 -year-olds in the renal study and 15.1 vs. $4.1 \mathrm{~L} / \mathrm{h}$ in the liver study). These results suggest that a dosing algorithm based on BSA alone is inadequate to deliver similar GCV exposures across the age ranges investigated in these 2 pediatric studies.

Because the bioavailability of GCV from p.o. valganciclovir solution was essentially independent of age and the drug is eliminated almost exclusively unchanged in the urine, we propose that renal function (assessed via CrCLS) should be included as a standard criterion in addition to BSA in future dosing algorithms for p.o. valganciclovir in children. Estimated $\mathrm{CrCL}$ has been used previously as a predictor of systemic GCV clearance in a dosing algorithm in a population pharmacokinetic model in adult SOT recipients (7). An individualized dosing algorithm for p.o. valganciclovir solution or tablets (where dose $=7 \times \mathrm{BSA} \times \mathrm{CrCL}$ ) has recently been shown in a pediatric population to provide GCV exposures similar to those obtained in adults, with age and type of SOT having limited impact on GCV pharmacokinetics. The dosing schedule used in this report was based on the data presented in this paper (16).

In our studies, the bioavailability and $C_{\max }$ of GCV from p.o. valganciclovir solution was similar to that previously obtained in adult SOT recipients $(44-71 \%$ [both studies] vs. $61 \%$ (17) and $5-7 \mathrm{mg} / \mathrm{L}$ [renal study] vs. $5-6 \mathrm{mg} / \mathrm{L}$ (5), respectively). Previous data have shown that the pharmacokinetics of GCV are generally similar between neonates, children, and adults (18-21).

Given the short duration of these studies, and the extensive use of concomitant medications, it is difficult to assess causality or draw conclusions regarding the overall safety profile.

Significant fluid shifts and ascitic fluid losses can occur in the first 2 weeks after liver transplantation, and could have potentially influenced GCV clearance values in the liver study. However, in our model, the type of SOT was not found to be a significant covariate for clearance of the drug.
The dosage was adjusted for reduced renal function based on estimated CrCL calculated using the Schwartz et al. formula (CrCLS) (12). The Schwartz et al. formula may overestimate glomerular filtration rate (GFR) in the pediatric population, particularly at GFR levels $<60 \mathrm{~mL} /$ $\min / 1.73 \mathrm{~m}^{2}$ (22). Nevertheless, CrCLS has good negative predictive value when CrCLS is $>20 \mathrm{~mL} / \mathrm{min} / 1.73 \mathrm{~m}^{2}$ (i.e., when CrCLS is $>20 \mathrm{~mL} / \mathrm{min} / 1.73 \mathrm{~m}^{2}$ there is a $95 \%$ chance that GFR measured by iothalamate clearance is $>15 \mathrm{~mL} /$ $\min / 1.73 \mathrm{~m}^{2}$ ) (22). As a baseline CrCL of $>45 \mathrm{~mL} / \mathrm{min} /$ $1.73 \mathrm{~m}^{2}$ was required for enrollment, overestimation of GFR with the Schwartz formula may be less of a concern (provided renal function remained stable during the study period).

The systemic exposure to GCV in pediatric renal or liver transplant recipients was similar after administration of p.o. valganciclovir solution $\left(520 \mathrm{mg} / \mathrm{m}^{2}\right)$ or IV GCV $(200 \mathrm{mg} /$ $\mathrm{m}^{2}$ ). As a dosing algorithm based only on BSA resulted in under-exposure of younger children, an algorithm including individually estimated $\mathrm{CrCL}$ and $\mathrm{BSA}($ dose $=7 \times \mathrm{BSA} \times$ $\mathrm{CrCL}$ ) is currently being investigated and should provide adequate GCVexposure in pediatric renal or liver transplant recipients for the prevention of CMV disease.

\section{Acknowledgments:}

The renal study was supported by the General Clinical Research Center (GCRC) and the Casey Lee Ball Foundation, and in part by GCRC grant PHS RR750 to M.D.P. Study coordinators were Peggy Munson (Wisconsin), Julie Starr (UCLA), Sharon Henson (Indianapolis), Jeanne Frances (Salt Lake City), Terry McClaine (Cincinnati), and Tiffany Schock (Ann Arbor). Funding for the studies was provided by F. Hoffmann-La Roche Ltd. We would like to thank the patients and their parents as well as Barbara Brennan from Hoffmann-La Roche (Nutley, New Jersey, USA) for critically reviewing the manuscript and Tracy Harrison and Richard Glover for editorial assistance provided under the guidance of M.D.P.

\section{References}

1. Snydman R. Epidemiology of infections after solid-organ transplantation. Clin Infect Dis 2001; 33 (Suppl 1): S5-S8.

2. Noble S, Faulds D. Ganciclovir: an update of its use in the prevention of cytomegalovirus infection and disease in transplant recipients. Drugs 1998; 56 (1): 115-146.

3. Flechner SM, Avery RK, Fisher R, et al. A randomized prospective controlled trial of oral acyclovir versus oral ganciclovir for cytomegalovirus prophylaxis in high-risk kidney transplant recipients. Transplantation 1998; 66: 1682-1688. 
4. Brennan DC, Garlock KA, Singer GG, et al. Prophylactic oral ganciclovir compared with deferred therapy for control of cytomegalovirus in renal transplant recipients. Transplantation 1997; 64 (12): 1843-1846.

5. Pescovitz MD, Rabkin J, Merion RM, et al.Valganciclovir results in improved oral absorption of ganciclovir in liver transplant recipients. Antimicrob Agents Chemother 2000; 44: 2811-2815.

6. McDiarmid SV, Jordan S, Kim GS, et al. Prevention and pre-emptive therapy of post-transplant lympho-proliferative disease in pediatric liver transplant recipients. Transplantation 1998; 66 (12): 1604-1611.

7. Wiltshire H, Hirankarn S, Farrell C, et al. Pharmacokinetic profile of ganciclovir after its oral administration and from its prodrug, valganciclovir, in solid organ transplant recipients. Clin Pharmacokinet 2005; 44 (5): 495-507.

8. Pescovitz MD, Jain A, Robson R, Mulgaonkar S, Freeman R, Bouw MR. Establishing pharmacokinetic bioequivalence of valganciclovir oral solution versus the tablet formulation. Transplant Proc 2007; 39: 3111-3116.

9. Daschner M. Drug dosage in children with reduced renal function. Pediatr Nephrol 2005; 20 (12): 1675-1686.

10. Sharkey I, Boddy AV, Wallace H, Mycroft J, Hollis R, Picton S. Body surface area estimation in children using weight alone: application in paediatric oncology. Br J Cancer 2001; 85 (1): 23-28.

11. Felici A,Verweij J, Sparreboom A. Dosing strategies for anticancer drugs: the good, the bad and body-surface area. Eur J Cancer 2002; 38 (13): 1677-1684.

12. Schwartz GJ, Feld LG, Langford DJ. A simple estimate of glomerular filtration rate in full-term infants during the first year of life. J Pediatr 1984; 104 (6): 849-854.
13. Mosteller RD. Simplified calculation of body-surface area. N Engl J Med 1987; 317 (17): 1098.

14. Tanner JM, Davies PS. Clinical longitudinal standards for height and height velocity for North American children. J Pediatr 1985; 107 (3): 317-329.

15. Cockcroft DW, Gault MH. Prediction of creatinine clearance from serum creatinine. Nephron 1976; 16 (1): 31-41.

16. Vaudry W, Ettenger R, Jara P, et al. on behalf of the WV16726 Study Group.Valganciclovir dosing according to body surface area and renal function in pediatric solid organ transplant recipients. Am J Transplant 2009; 9 (3): 636-643.

17. Jung D, Dorr A. Single-dose pharmacokinetics of valganciclovir in HIV- and CMV-seropositive subjects. J Clin Pharmacol 1999; 39 (8): 800-804.

18. Trang JM, Kidd L, Gruber W, et al. Linear single-dose pharmacokinetics of ganciclovir in newborns with congenital cytomegalovirus infections. NIAID Collaborative Antiviral Study Group. Clin Pharmacol Ther 1993; 53 (1): 15-21.

19. Markham A, Faulds D. Ganciclovir. An update of its therapeutic use in cytomegalovirus infection. Drugs 1994; 48 (3): 455-484.

20. Pescovitz MD, Brook B, Jindal RM, Leapman SB, Milgrom ML, Filo RS. Oral ganciclovir in pediatric transplant recipients: a pharmacokinetic study. Clin Transplant 1997; 11 (6): 613-617.

21. Jacqz-Aigrain E, Macher MA, Sauvageon-Marthe H, Brun P, Loirat C. Pharmacokinetics of ganciclovir in renal transplant children. Pediatr Nephrol 1992; 6 (2): 194-196.

22. Seikaly MG, Loleh S, Rosenblum A, Browne R.Validation of the Center for Medicare and Medicaid Services algorithm for eligibility for dialysis. Pediatr Nephrol 2004; 19: 893-897. 